\title{
Response-specific sex difference in the retention of fear extinction
}

\author{
Meagan E. Voulo and Ryan G. Parsons \\ Department of Psychology, Stony Brook University, Stony Brook, New York 11794, USA
}

\begin{abstract}
Fear conditioning studies in rodents allow us to assess vulnerability factors which might underlie fear-based psychopathology such as post-traumatic stress disorder (PTSD). Despite PTSD being more prevalent in females than males, very few fear conditioning studies in rodents have tested females. Our study assessed fear conditioning and extinction in male and female rats using both fear-potentiated startle and freezing behavior as measures. Rats were trained to fear cues that predicted the occurrence of shock and then subsequently exposed to an extinction training procedure where the cue was presented repeatedly in the absence of shock. Retention of the extinction memory was assessed the next day. Our results showed that females exhibited less retention of fear extinction, but only when measured by fear-potentiated startle. Our results highlight the importance of using multiple indices of fear behavior, particularly when comparing sexes on measures of extinction learning.
\end{abstract}

Not all individuals who experience trauma during their lifetime will develop post-traumatic stress disorder (PTSD). One of the greatest risk factors for developing this disorder is being female, with the lifetime prevalence rate twice as high for women as it is for men (Kessler et al. 1995; Kilpatrick et al. 2013). Fear conditioning studies in rodents allow us to study the behavioral and neural mechanisms that may underlie PTSD (Parsons and Ressler 2013), yet very few fear conditioning studies in rodents have used females as subjects (Lebron-Milad and Milad 2012). Despite the increased prevalence of PTSD and other fear and anxiety-based disorders in females, nonhuman animal studies testing for sex differences in fear conditioning have largely failed to capture this difference.

Fear conditioning studies typically use a procedure in which a discrete cue (e.g., auditory stimulus) signals the occurrence of an aversive stimulus, usually a brief shock. Under normal circumstances, animals learn to fear the discrete cue associated with shock and will also learn to fear the context (i.e., place) in which shock occurs. A handful of studies have directly compared animals of both sexes on tests of cued and contextual fear conditioning. Some of these reports have shown that while males and females exhibit equivalent levels of fear conditioning to discrete cues (Maren et al. 1994; Baran et al. 2009; Milad et al. 2009a; Barker and Galea 2010; Gruene et al. 2015a; Fenton et al. 2016), males often show evidence of better contextual conditioning (Maren et al. 1994; Chang et al. 2009; Barker and Galea 2010). Other studies have tested for sex differences in fear extinction learning, a form of learning through which animals learn to inhibit responding to cues that once signaled an aversive event. Over the last several years, the study of fear extinction has received considerable attention (Milad and Quirk 2012) due in part to the fact that humans with PTSD display impaired extinction (Milad et al. 2009b; Norrholm et al. 2011). Recent findings in rodents are mixed with regard to sex differences in fear extinction with several studies reporting no difference between males and females (Milad et al. 2009a; Rey et al. 2014; Gruene et al. 2015a), while others have found that females show weaker fear extinction (Baran et al. 2009, 2010; Matsuda et al. 2015; Fenton et al. 2016). Moreover, other studies have found that the retention of extinction learning in female rats varies depending on estrus stage

\section{Corresponding author: ryan.parsons@stonybrook.edu}

Article is online at http://www.learnmem.org/cgi/doi/10.1101/Im.045641.117. such that rats exposed to extinction training while in proestrus show better retention of extinction (Milad et al. 2009a; Rey et al. 2014).

While the evidence is varied regarding sex differences in fear conditioning and extinction, one shortcoming of the existing work is that the majority of the previous studies in rodents have used a single measure, freezing behavior, as an index of learning. As others have noted (Dalla and Shors 2009), apparent sex differences in learning and memory, or lack thereof, might instead reflect differences in behavioral performance. In the case of freezing behavior, differences in activity levels between males and females might complicate the interpretation of experiments which use inactivity as an index of fear. This issue is highlighted by a recent observation that female rats exhibit an active conditioned fear response (i.e., darting) that is not frequently seen in males (Gruene et al. 2015b). To further characterize the effect of sex on measures of fear conditioning and extinction, in the current study we compared levels of fear conditioning and extinction in males and females using both freezing behavior and fearpotentiated startle as measures.

\section{Results}

In the first experiment (Fig. 1A), we trained female $(N=14)$ and male $(N=14)$ Sprague-Dawley rats in a fear conditioning task during which they received two pairings of a tone $(4 \mathrm{kHz}, 76 \mathrm{~dB}, 30$ $\mathrm{sec})$ and footshock (1.0 mA, $1.0 \mathrm{sec})$ delivered through the floor of the testing chambers. For extinction training, all rats were placed in a context which differed from the training context and presented with 20 presentations of the tone in the absence of shock. To test for the retention of extinction, rats were returned to the extinction context $24 \mathrm{~h}$ later and given eight additional presentations of the tone in the absence of shock. Freezing behavior was measured throughout all of the testing sessions. Figure 1B shows the results of the experiment assessing fear conditioning and extinction in male and female rats (Experiment 1). There

(C) 2017 Voulo and Parsons This article is distributed exclusively by Cold Spring Harbor Laboratory Press for the first 12 months after the full-issue publication date (see http://learnmem.cshlp.org/site/misc/terms.xhtml). After 12 months, it is available under a Creative Commons License (AttributionNonCommercial 4.0 International), as described at http://creativecommons. org/licenses/by-nc/4.0/. 
A

Fear Conditioning

$2 x$ tone- $1 \mathrm{~mA} / 1 \mathrm{~s}$ shock

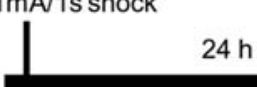

B

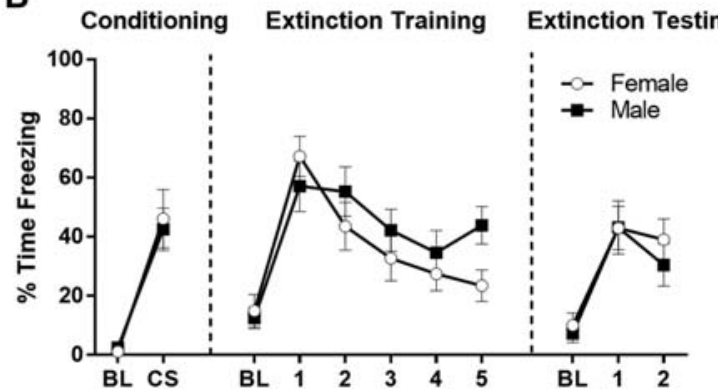

Extinction Training
Extinction Testing

$24 \mathrm{~h}$

C

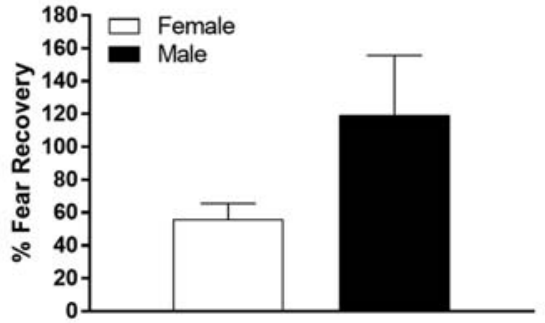

D Acoustic Startle

Fear Conditioning

Pre-extinction test

Extinction training

Post-extinction test

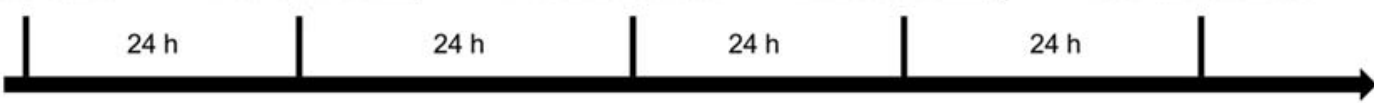

E

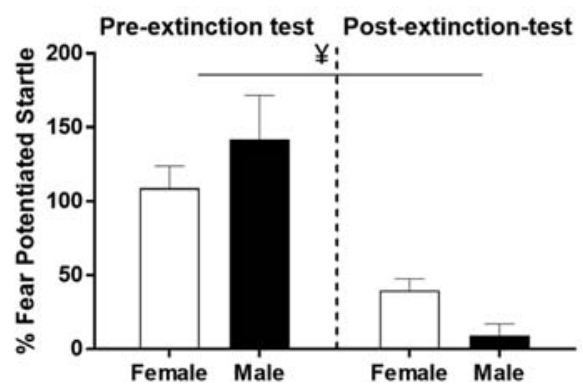

F

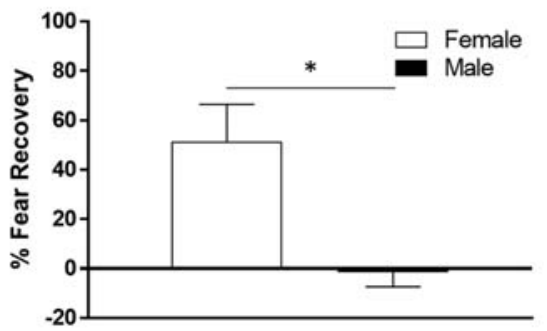

Figure 1. (A) Timeline of freezing behavior protocol for experiment 1. (B) Male and female freezing behavior during fear conditioning, extinction training, and extinction testing for experiment 1 . BL indicates baseline freezing during the acclimation period prior to presentation of the CS. CS indicates the average freezing to the two CS presentations during conditioning. Points during extinction training and testing are blocks of four CS trials. (C) Male and female fear recovery scores derived from first four CS trials during testing divided by first four CS trials during training expressed as a percentage. (D) Timeline of fear-potentiated startle protocol for experiment 2. (E) Fear-potentiated startle values in males and females during the preextinction and postextinction tests for experiment 2 . Females showed poorer retention of extinction. $¥$, denotes a significant sex $\times$ test session interaction. $(F)$ Fear recovery values in male and female rats for experiment 2 . Females showed significantly more fear-potentiated startle indicating a disruption in the retention of extinction. $\left(^{*}\right) P<0.05$.

was no difference in freezing behavior between groups during the baseline $\left(t_{(26)}=-1.573, P=0.132\right)$ or CS periods during conditioning $\left(t_{(26)}=0.852, P=0.402\right)$. During extinction training, males and females did not significantly differ in their baseline freezing values, $t_{(26)}=-0.385, P=0.703$. To compare withinsession extinction between males and females on the extinction training day, we computed a repeated-measures ANOVA with time (five blocks of four CS trials) as a within-subjects factor and sex as a between subjects factor. The results uncovered a significant effect of time $\left(F_{(1,26)}=19.122, P<0.001\right)$ indicating that freezing decreased during the extinction training session. There was no main effect of sex, $F_{(1,26)}=0.588, P=0.450$, and no time by sex interaction $\left(F_{(2.902,26)}=2.186, P=0.099\right.$; GreenhouseGeisser corrected). During extinction testing, males and females did not significantly differ in their baseline freezing values, $t_{(26)}=0.509, P=0.615$. To compare extinction retention between males and females, we computed a repeated-measures ANOVA comparing freezing levels during the two blocks of four trials during the extinction test. There was no main effect of block, but a trend toward a decrement in freezing, $F_{(1,26)}=968.41, P=$ 0.063 . There was no significant interaction between sex and block, $F_{(1,26)}=268.08, P=0.317$, and no main effect of sex, $F_{(1,26)}=$ $250.226, P=0.689$. This suggests that males and females showed similar levels of extinction retention. We also computed a fear recovery score by taking the average time spent freezing to the first four CS trials of extinction testing, dividing it by the first four CS trails of extinction training, and expressing it as a percentage. Figure $1 \mathrm{C}$ shows the male and female fear recovery values. There was no significant difference between male and female fear recovery scores $\left(t_{(26)}=1.76, P=0.099\right)$.

Next, we tested a separate group of female and male rats on fear conditioning and extinction using fear-potentiated startle as the behavioral measure (Fig. 1D). Baseline acoustic startle was assessed on two consecutive days prior to fear conditioning. A $t$-test showed no difference between groups on baseline startle amplitude $\left(t_{(29)}=1.174, P=0.250\right)$. Rats were then trained with 10 pairings of a light (4-sec, $\sim 82$ lux) that predicted shock $(0.5 \mathrm{sec}$, $0.4 \mathrm{~mA}$ ). To assess levels of fear prior to extinction training, rats 
were given a "preextinction" test $24 \mathrm{~h}$ after fear conditioning. During the preextinction test, rats were exposed to startle trials, some of which occurred in the presence of the light cue. Fear-potentiated startle to the light was assessed by averaging startle amplitudes in the presence of light and expressing it as a percentage of startle trials that occurred in the absence of light. The next day, rats were given an extinction training session which involved presenting the light cue 30 times in the absence of shock (or the startle stimulus). To test for the retention of extinction, rats were given a "post-extinction" test the following day which was identical to the preextinction test. To determine whether there was a difference between sexes on the initial learning and expression of fear, we computed a $t$-test comparing percent potentiation values during the preextinction test. This test indicated no significant difference between male and female rats during the preextinction test $\left(t_{(29)}=1.174, P=0.250\right)$. To compare extinction retention between males and females, a repeated-measures ANOVA was used with session (preextinction and post-extinction) as a within-subjects factor and sex as a between subjects factor. The results uncovered a significant effect of session $\left(F_{(1,29)}=45.71, P<0.001\right)$, indicating that fear levels decreased from the pre- to post-extinction test session. There was no main effect of $\operatorname{sex}\left(F_{(1,29)}=0.06, P=0.811\right)$, however there was a significant session by sex interaction $\left(F_{(1,29)}=4.44, P=\right.$ $0.044)$. A $t$-test confirmed that female rats showed significantly higher fear-potentiated startle during the post-extinction test $\left(t_{(29)}=-2.70, P=0.012\right)$ (Fig. 1E). Because the significant interaction might have been partially driven by the small difference in preextinction scores, we calculated a "fear recovery" score by dividing each rat's post-extinction value by its preextinction score and expressing it as a percentage. The results of a $t$-test on fear recovery values revealed a significant difference such that females showed more fear recovery than males $\left(t_{(29)}=-2.70\right.$, $P=0.012$ )(Fig. 1F).

The results from the first set of findings suggest that sex differences in fear extinction are revealed when fear-potentiated startle is measured, but not when freezing behavior is assessed. Alternatively, differences in the experimental protocol between the fear-potentiated startle and freezing experiments including the number of trials and intensity of the footshock during conditioning, the presence of a pretest session prior to extinction train- ing, and the number of extinction trials may have influenced our findings. To test whether these factors dictated the presence of sex difference in fear extinction, and not the measure of fear used, we conducted two additional experiments.

First, we measured freezing behavior in male $(N=10)$ rats and female $(N=10)$ rats exposed to auditory fear conditioning using the same parameters as in the initial freezing experiment (Fig. 2A). All animals were then exposed to pretest, extinction training, and post-test sessions with the same number, duration, and spacing of CS trials as those used in our fear-potentiated startle experiment. $T$-tests revealed no difference in freezing behavior between groups during the baseline $\left(t_{(18)}=0.941, P=0.359\right)$ or CS periods during conditioning $\left(t_{(18)}=-0.259, P=0.799\right)$. To determine whether there was a difference between sexes in memory for fear conditioning, we computed $t$-tests comparing the average freezing values during the baseline period and 10 CS trials in the preextinction test. These tests indicated no significant difference between male and female rats during the baseline period $\left(t_{(15)}=-0.232, P=0.819\right)$ or during the CS trials $\left(t_{(18)}=\right.$ $0.736, P=0.471)$. To compare freezing levels during the extinction training session, we computed a repeated-measures ANOVA with time (six blocks of five CS trials) as a within-subjects factor and sex as a between subjects factor. Figure $2 \mathrm{~B}$ shows the results of this test, which indicated a significant effect of time on freezing behavior such that freezing decreased throughout the session $\left(F_{(2.455,36.822)}=19.674, \quad P<0.001\right)$. There was no significant time by sex interaction $\left(F_{(2.455,36.822)}=2.177, P=0.118\right)$ and no significant effect of $\operatorname{sex}\left(F_{(1,15)}=3.19, P=0.094\right)$ (GreenhouseGeisser correction used for within-subjects effects). To compare extinction retention between sexes, we computed a repeatedmeasures ANOVA with session as a within-subjects factor and sex as a between-subjects factor. The results uncovered a significant effect of session, $F_{(1,18)}=23.138, P<0.001$, such that freezing decreased from pre- to post-test. There was no effect of sex, $F_{(1,18)}=0.760, P=0.395$, and no session by sex interaction, $F_{(1,18)}=0.057, P=0.814$. We also performed a $t$-test on "fear recovery" scores (Fig. 2C), which yielded no significant difference between males and females $\left(t_{(18)}=0.044, P=0.965\right)$.

Next, we conducted another experiment in which freezing behavior was measured in male $(N=8)$ rats and female $(N=7)$ rats using a conditioning protocol with the same number,

A

Fear Conditioning

$2 \mathrm{x}$ tone-1mA/1s shock Pre-extinction test Extinction training Post-extinction test

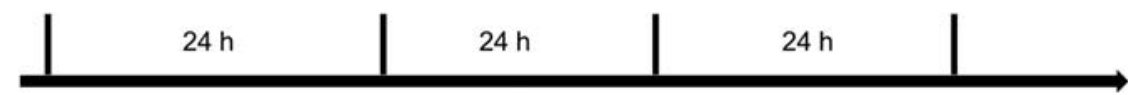

B

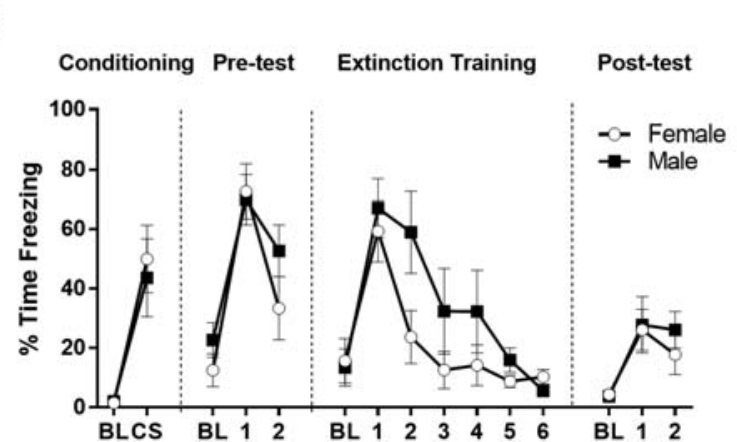

C

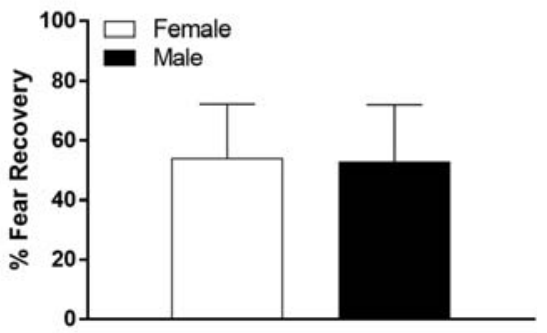

Figure 2. (A) Timeline of freezing behavior protocol for experiment 3. (B) Male and female freezing behavior during fear conditioning, preextinction testing, extinction training, and post-extinction testing. BL indicates baseline freezing during the acclimation period prior to presentation of the CS. CS indicates the average freezing to the two CS presentations during conditioning. Points during the pretest, extinction training, and post-test are blocks of five CS trials. (C) Fear recovery values in male and female rats. 
duration, and intensity of shock as used in our fear-potentiated startle experiments. After conditioning, the animals underwent extinction training and testing as described above in experiment 1 (Fig. 3A). Figure 3B shows the results of the freezing behavior during conditioning, pretest, extinction training, and post-test. There was no difference in freezing behavior between groups during the baseline period during conditioning $\left(t_{(13)}=-1.797, P=\right.$ 0.096), however males froze significantly more during the CS period $\left(t_{(13)}=-4.471, P=0.001\right)$. To further investigate this difference, we computed a repeated-measures ANOVA with blocks of two trials as a within-subjects factor and sex as a between subjects factor. We uncovered a significant effect of block, $F_{(4,52)}=24.021$, $P<0.001$, such that freezing increased after block 1 . We also found a significant effect of sex, $F_{(1,13)}=19.994, P=0.001$, such that males froze more than females. However, there was no block by sex interaction, $F_{(4,52)}=1.273, P=0.292$, indicating that their pattern of freezing did not differ between groups as a function of time. During extinction training, males and females did not significantly differ in their baseline freezing values, $t_{(13)}=1.263, P=0.229$. To compare freezing behavior on extinction training day, we computed a repeated-measures ANOVA with time (five blocks of four CS trials) as a within-subjects factor and sex as a between subjects factor. The results uncovered a significant effect of time $\left(F_{(2.177,28.297)}=4.782, \quad P=0.014\right.$; Greenhouse-Geisser corrected) indicating that freezing decreased during the extinction training session. There was no main effect of sex, $F_{(1,13)}=1.440, P=0.251$, and no time by sex interaction $\left(F_{(2.177,28.297)}=0.357, P=0.720 ;\right.$ Greenhouse-Geisser corrected $)$. During extinction testing, males and females did not significantly differ in their baseline freezing values, $t_{(13)}=0.847, P=0.413$. To compare extinction retention between males and females, we computed a repeated-measures ANOVA comparing freezing levels during the two blocks of four trials during the extinction test. There was no main effect of block $\left(F_{(1,13)}=114.375, P=0.390\right)$, no significant interaction between sex and block $\left(F_{(1,13)}=\right.$ $38.055, P=0.617)$, and no main effect of sex $\left(F_{(1,13)}=0.013\right.$, $P=0.910)$. We also computed fear recovery scores as mentioned above (Fig. 3C), which showed no significant difference in fear recovery scores between males and females $\left(t_{(13)}=-0.557, P=\right.$ 0.587). Altogether, these data indicate that males and females showed similar levels conditioning and extinction when freezing was the dependent measure.

A
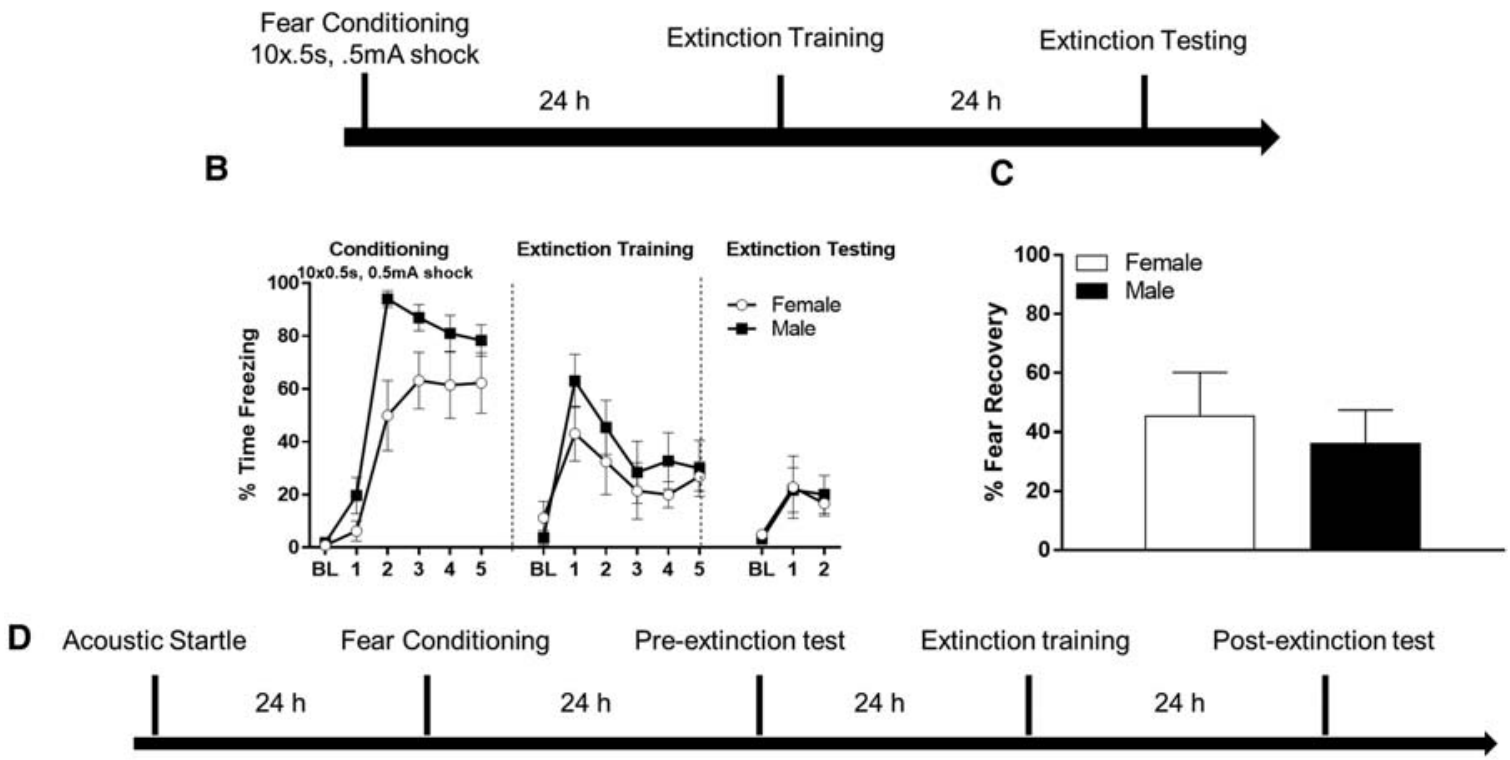

E

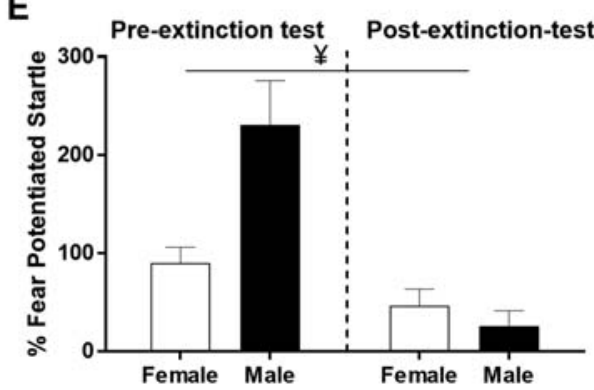

$\mathbf{F}$

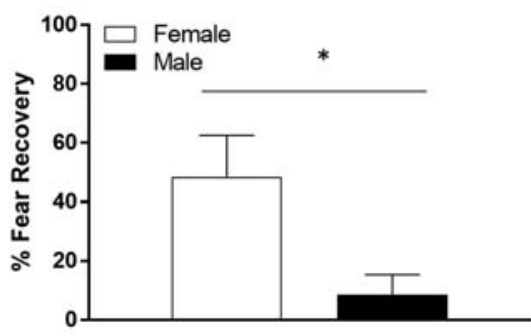

Figure 3. (A) Timeline of freezing behavior protocol in experiment 4a. (B) Male and female freezing behavior during fear conditioning, extinction training, and extinction testing for experiment 1. BL indicates baseline freezing during the acclimation period prior to presentation of the CS. Points during fear conditioning indicate the average freezing to blocks of two CS-US trials. Points during extinction training and testing are blocks of four CS trials. (C) Male and female fear recovery scores derived from first four CS trials during testing divided by first four CS trials during training expressed as a percentage. (D) Timeline of fear-potentiated startle protocol in experiment $4 \mathrm{~b}$. (E) Fear-potentiated startle values in males and females during the preextinction and postextinction tests for experiment $4 \mathrm{~b}$. Females showed poorer retention of extinction. $¥$, denotes a significant sex $\times$ test session interaction. $(F)$ Fear recovery values in male and female rats for experiment $4 \mathrm{~b}$. Females showed significantly more fear-potentiated startle indicating a disruption in the retention of extinction. $(*) P<0.05$. 
Finally, we trained the same rats $(N=15)$ used in the prior experiment with 10 pairings of light and shock, as in the prior fearpotentiated startle experiment (Fig. 3D). To determine whether there was a difference between sexes in memory for fear conditioning, we computed a $t$-test comparing percent potentiation values during the preextinction test. This test indicated a significant difference between male and female rats during the preextinction test such that males had higher potentiation values than females $\left(t_{(13)}=2.975, P=0.011\right)$. Figure $3 \mathrm{E}$ shows the preextinction and post-extinction potentiation values for males and females. To compare extinction retention between males and females, a repeated-measures ANOVA was used with session (preextinction and post-extinction) as a within-subjects factor and sex as a between subjects factor. The results uncovered a significant effect of session $\left(F_{(1,13)}=48.636, P<0.001\right)$, indicating that fear levels decreased from the pre- to post-extinction test session. There was no main effect of sex $\left(F_{(1,13)}=3.459, P=0.086\right)$, however there was a significant session by sex interaction $\left(F_{(1,13)}=\right.$ $20.628, P=0.001)$, with male rats showing a greater decrement in potentiation values from pre- to post-test than female rats. Because the significant interaction might have been partially driven by the difference in preextinction scores, we calculated fear recovery scores using the same method as mentioned above. The results of a $t$-test on fear recovery values revealed a significant difference such that females showed more fear recovery than males, which is displayed in Figure $3 \mathrm{~F}\left(t_{(13)}=-2.890, P=0.013\right)$.

\section{Discussion}

The current study tested for sex differences in fear acquisition and extinction using both freezing behavior and fear-potentiated startle as response measures. Our primary finding was that females showed a deficit in the retention of extinction when measured by fear-potentiated startle, but not freezing behavior. Importantly, this observation was consistent even when conditioning and extinction was tested within the same animals using both measures of fear. When measuring freezing to a cue that had been paired with shock, we found that male and female rats showed comparable levels of freezing behavior during extinction training and extinction testing. In one experiment, male rats froze more during the conditioning session, although this difference was not reflected in levels of freezing during subsequent test sessions. It is possible that the increased number of trials and reduced shock intensity made apparent a difference that is difficult to observe with fewer trials. In the same experiment, rats were subsequently put through conditioning and extinction procedures while measuring fear-potentiated startle. Males showed higher levels of fearpotentiated startle before extinction, which we did not observe in our prior experiment. It is possible this difference was the result of prior training and testing, however it is important to note that even with the males showing more fear-potentiated startle before extinction, the females still showed a deficit in the retention of extinction. Overall, our findings stress the importance of using multiple behavioral measures of fear learning, particularly when comparing males and females.

If sex differences in fear extinction only emerge when measuring certain responses, an important question to consider is why fear-potentiated startle is sensitive to detecting this difference, while freezing behavior is not. The answer to this question may lie with evidence that female and male rodents exhibit different behavioral repertoires when presented with a threat. Several studies have shown that females show superior performance when active responses are measured whether it be classical eyeblink conditioning (Wood and Shors 1998; Dalla et al. 2009), fear conditioning (Gruene et al. 2015b), or avoidance tasks (Steenbergen et al. 1990; Dalla et al. 2008). Thus, it is possible that the ten- dency for females to engage in more active fear responses obscures reliable sex differences in conditioning and/or extinction when freezing behavior is the only measure. The startle response likely has an acute protective function, but it might also serve to facilitate escape and avoidance behavior. Thus, our observation that females show poorer fear-potentiated startle might be related to the tendency for females to engage in more active fear responses than males.

If our findings reflect divergence in defensive response patterns between sexes, an important next step will be to identify the neurobiological correlates underlying this difference. The majority of fear responses are organized in the medial division of the central nucleus of the amygdala which sends projections to various anatomical regions that mediate behavioral expressions of fear (Davis and Whalen 2001). While these projections have been known for some time now, studies have begun to identify circuits within the central nucleus that govern whether active or passive fear responses are expressed (e.g., Gozzi et al. 2010). Other recent work has identified specific cell types in the central nucleus which favor the expression of passive fear behavior (i.e., freezing), while other cell types drive the expression of active fear responses (Yu et al. 2016; Fadok et al. 2017). It is tempting to speculate that the balance of these mechanisms might be shifted in females such that they are more likely to engage in active fear responses.

One shortcoming of the current study is that by measuring conditioning and extinction in free cycling female rats, our experiments were not able to assess the effect of estrus phase on fear conditioning and extinction. Vaginal cytology was performed on all females in the experiments, however small sample sizes precluded meaningful statistical analysis of these data. Prior studies have reported that the stage of the estrous cycle during extinction training can affect extinction of fear such that rats trained in proestrus show better retention of extinction (Milad et al. 2009a), likely as the result of high estrogen levels during this phase (Rey et al. 2014; Graham and Daher 2016). Future studies will assess the effect of estrus on conditioning and extinction using both measures of fear we used here.

There are very few studies directly comparing males and females on fear-potentiated startle, and those that exist are conflicting with respect to differences in the acquisition and expression of fear-potentiated startle (de Jongh et al. 2005; Toufexis et al. 2005). We did not observe a consistent difference between sexes in fearpotentiated startle levels prior to extinction, however females showed significantly higher levels of fear after extinction. To the best of our knowledge, this is the first study comparing extinction in males and females using fear-potentiated startle. Females have twofold higher rates of PTSD, and PTSD is associated with impaired extinction (Milad et al. 2009b; Glover et al. 2012), yet prior studies of fear extinction in rodents have largely failed to detect a consistent difference between sexes. While a combination of factors likely explains the discrepant findings regarding sex differences in fear extinction in previous studies, our data suggest the fact that most prior work measured freezing behavior was a contributing factor. Going forward studies which use measures like fear-potentiated startle, which can also be studied in humans, might be advantageous in translating studies in rodents to humans.

\section{Materials and Methods}

\section{Subjects}

Male and female Sprague-Dawley rats (Charles River Laboratories, Raleigh, NC) $\sim 8-10$ wk of age served as subjects. Rats were housed in groups of two in plastic boxes with food and water available ad libitum. Rats were kept in a colony room that was maintained on a 12-h light-dark cycle (lights on at 7 a.m.), and all behavioral procedures occurred during the rats' light cycle. Each rat was handled 
for $\sim 5$ min each day for $7 \mathrm{~d}$ prior to the start of the experiment. Handling days 1-4 took place in the colony room and days 5-7 took place in the behavior laboratory. All procedures were approved by the Institutional Animal Care and Use Committee at Stony Brook University.

\section{Apparatus}

\section{Freezing behavior}

All training and testing procedures took place in four identical freezing chambers $(32 \times 26 \times 21 \mathrm{~cm})$ (Clever Systems) made of Plexiglas and stainless steel and housed in sound-attenuating boxes. During fear conditioning, a footshock was delivered through the floor which was composed of stainless steel rods. Each chamber was illuminated by a $28 \mathrm{~V}$ miniature white light bulb, and fans mounted on the boxes provided background noise of $\sim 60 \mathrm{~dB}$ (Context A). On extinction training and testing days, the context was altered such that infrared LED lights illuminated the chambers, painted metal inserts covered the floor and walls of the chambers, and 5\% acetic acid solution was used to clean the chambers before each set of animals (Context B). Stimuli used during the experiments were under the control of FreezeScan 1.0 software (Clever Systems) on a Windows workstation computer.

\section{Fear-potentiated startle}

Four identical $40.64 \times 40 \times 49.53 \mathrm{~cm}($ depth $\times$ width $\times$ height $)$ sound-attenuating cabinets were used (Startle Monitor II, Kinder Scientific). During fear conditioning, rats were placed in four $26.67 \times 20.96 \times 15.9 \mathrm{~cm}$ (depth $\times$ width $\times$ height) identical Plexiglas and stainless steel cages. The floor of each cage was made of stainless steel bars through which shock could be delivered. For baseline startle, testing, and extinction training sessions, rats were placed in restrainers of different size and shape and made of material dissimilar from the cages used during conditioning. The restrainers had a floor made of plastic and a rounded cover composed of stainless steel rods. Both the startle and shock cages sat on top of a load cell sensing platform on the floor of the cabinet. A single pulse calibrator by StartleMonitor II Version 8.15 (Kinder Scientific) interfaced to a PC reported the output in Newtons $(\mathrm{N})$. Startle amplitude was defined as the maximum $\mathrm{N}$ that occurred during the first $500 \mathrm{msec}$ after the onset of the white noise burst. Startle responses were elicited by $50-\mathrm{msec} 95-\mathrm{dB}$ white noise bursts delivered through high-frequency speakers mounted in the ceiling inside the chambers $\sim 20 \mathrm{~cm}$ from the load cell sensing platform. Background noise was $\sim 52 \mathrm{~dB}$. Sound levels were calibrated using with a sound level meter. The unconditioned stimulus was a 0.5 -sec $0.4-\mathrm{mA}$ shock delivered through the floor bars. Shocks were produced by DSCK Dual Programmable Shockers (Kinder Scientific). The conditioned stimulus was a 4-sec light $\sim 82$ lux delivered through an LED light panel positioned on the ceiling of the cabinets.

\section{Behavioral procedures}

\section{Experiment 1: fear conditioning and extinction measured by freezing behavior}

Fear Conditioning: Rats were placed into context A and received two pairings of an auditory conditioned stimulus (CS) with a footshock unconditioned stimulus (UCS) following a 6-min acclimation period. A $4 \mathrm{kHz}$ tone $(30 \mathrm{sec} / 76 \mathrm{~dB}$ ) served as the CS, while a $1.0 \mathrm{sec} / 1 \mathrm{~mA}$ footshock served as the UCS. There was a 2 -min intertrial interval (ITI) between the two trials. Extinction Training and Testing: Approximately $24 \mathrm{~h}$ after fear conditioning rats were placed into context B and received 20 presentations (2-min ITI) of the CS in the absence of shock following a 6-min acclimation period. Extinction testing occurred about $24 \mathrm{~h}$ after extinction training and was identical to the extinction training procedure with the exception that only eight trials of the CS were presented
Experiment 2: fear conditioning and extinction measured by fear-potentiated startle

Baseline startle: On two consecutive days rats were placed into the startle chambers, and following a 5-min acclimation period, were presented with $3095 \mathrm{~dB}$ noise bursts with a 30-sec interstimulus interval (ISI). Fear conditioning: The next day rats were placed in the shock cages and presented with 10 light-footshock pairings following a 5-min acclimation period. The CS was a 4 sec light at $\sim 82$ lux. The US was a 0.5 -sec shock produced by a shock generator at a $0.4 \mathrm{~mA}$ intensity. The intertrial interval (ITI) was $4 \mathrm{~min}$. Preextinction test: To test for memory of fear conditioning before extinction training, rats were returned to the startle chambers the next day. After the 5-min acclimation period, they were presented with thirty $95 \mathrm{~dB}$ noise bursts (leader trials) in order to habituate the startle response before the testing trials occurred. Rats were then presented with 40 additional noise bursts, 10 of which occurred in the presence of the startle stimulus, and 30 that did not. Extinction training: Rats were returned to the startle chambers the next day and received thirty 4 -sec presentation of the light CS in the absence of shock (30-sec ITI). Post extinction test: The final day, rats were returned to the startle chambers and the preextinction test procedure was repeated.

Experiment 3: fear conditioning and extinction measured by freezing behavior Fear Conditioning: The fear conditioning procedure was identical to that described in Experiment 1. Preextinction test: Approximately $24 \mathrm{~h}$ after fear conditioning rats were placed into context $\mathrm{B}$ and received 10 presentations ( 90 -sec ITI) of the CS in the absence of shock following a 5-min acclimation period. Extinction Training: Approximately $24 \mathrm{~h}$ after the preextinction test rats were placed into context B and received 30 presentations (30-sec ITI) of the $\mathrm{CS}$ in the absence of shock following a 5-min acclimation period. Post extinction test: The final day, rats were returned to context B and the preextinction test procedure was repeated.

\section{Experiment 4: fear conditioning and extinction measured by freezing behavior and fear-potentiated startle}

Fear Conditioning: Rats were placed into context A and received ten CS-UCS pairings (4-min ITI) following a 5-min acclimation period. A 4-kHz tone $(30 \mathrm{sec} / 76 \mathrm{~dB})$ served as the CS, which coterminated with a 0.5 sec $0.4-\mathrm{mA}$ footshock UCS. Extinction Training and Testing: Approximately $24 \mathrm{~h}$ after fear conditioning rats were placed into context B and received 20 presentations (2-min ITI) of the CS in the absence of shock following a 6-min acclimation period. Extinction testing occurred $\sim 24 \mathrm{~h}$ after extinction training and was identical to the extinction training procedure with the exception that only eighty trials of the CS were presented. Fear-potentiated startle conditioning and extinction: Rats were exposed to conditioning, extinction training, and testing as described in Experiment 2.

\section{Vaginal cytology}

For all female rats in the experiment, vaginal smears were taken each day during the handling procedure and during behavioral testing. The smears were placed on slides, stained with cresyl violet, and examined under a microscope to determine phases of the estrous cycle. Phases were identified by the proportion of leukocytes, nucleated, and cornified cells in each sample (Cora et al. 2015).

\section{Data analysis}

\section{Freezing behavior}

A live video recording captured the behavior of each rat. The amount of movement was determined by calculating the frame-by-frame changes in pixels using the FreezeScan 1.0 software (Clever Systems). The principal investigator hand-scored preliminary videos in order to set the computer scoring parameters 
that most closely matched hand-scoring methods to measure the animals' freezing behavior. The dependent variable used for the analyses was the percentage of total time spent freezing during the 30-sec tone and during the acclimation periods prior to presentation of the CS and/or UCS. To analyze within-session extinction, we averaged CS trials into 4 (Experiment 1) or 5 (Experiment 3 ) trials blocks during the extinction training session. To analyze extinction retention, we computed freezing levels in two four-trial blocks and used a repeated-measures ANOVA to test for changes in freezing over time and between groups. We also calculated a fear recovery score by taking the average of all eight CS trials during extinction testing, dividing it by the average of the first eight CS trials during extinction training, and expressing it as a percentage. These data were analyzed with Student's $t$-test using SPSS.

\section{Fear-potentiated startle}

To quantify fear-potentiated startle during the preextinction and post-extinction tests, the mean startle amplitude for each rat during the 30 leader trials and 10 light test trials was determined and a percent potentiation score was calculated by subtracting the leader trials from the light-tone trials, dividing by the leader trials, and multiplying by 100 (Walker and Davis 2002). We also calculated a fear recovery score by taking the average percent potentiation of all $10 \mathrm{CS}$ trials during the post-extinction test, dividing it by the average of the 10 CS trials during the preextinction, and expressing it as a percentage. Data were analyzed using repeated-measures ANOVA or Student's $t$-test using SPSS.

\section{Acknowledgments}

This work was supported by funds from Stony Brook University. We thank A. Russo and J. Lee for technical assistance, and Dr. Maricedes Acosta-Martinez for help with the vaginal cytology.

\section{References}

Baran SE, Armstrong CE, Niren DC, Hanna JJ, Conrad CD. 2009. Chronic stress and sex differences on the recall of fear conditioning and extinction. Neurobiol Learn Mem 91: 323-332.

Baran SE, Armstrong CE, Niren DC, Conrad CD. 2010. Prefrontal cortex lesions and sex differences in fear extinction and perseveration. Learn Mem 17: 267-278.

Barker JM, Galea LAM. 2010. Males show stronger contextual fear conditioning than females after context pre-exposure. Physiol Behav 99: 82-90.

Chang Y, Yang C, Liang Y, Yeh C, Huang C, Hsu K. 2009. Estrogen modulates sexually dimorphic contextual fear extinction in rats through estrogen receptor B. Hippocampus 19: 1142-1150.

Cora MC, Kooistra L, Travlos G. 2015. Vaginal cytology of the laboratory rat and mouse: review and criteria for the staging of the estrous cycle using stained vaginal smears. Toxicol Pathol 43: 776-793.

Dalla C, Shors TJ. 2009. Sex differences in learning processes of classical and operant conditioning. Physiol Behav 97: 229-238.

Dalla C, Edgecomb C, Whetstone AS, Shors TJ. 2008. Females do not express learned helplessness like males do. Neuropsychopharmacology 33: $1559-1569$.

Dalla C, Papachristos EB, Whetstone AS, Shors TJ. 2009. Female rats learn trace memories better than male rats and consequently retain a greater proportion of new neurons in their hippocampi. Proc Natl Acad Sci 106: 2927-2932.

Davis M, Whalen PJ. 2001. The amygdala: vigilance and emotion 42 . Mol Psychiatry 6: $13-34$

de Jongh RL, Geyer MA, Olivier B, Groenink L. 2005. The effects of sex and neonatal maternal separation on fear-potentiated and light-enhanced startle. Behav Brain Res 161: 190-196.

Fadok JP, Krabbe S, Markovic M, Courtin J, Xu C, Massi L, Botta P, Bylund K, Muller C, Kovacevic A, et al. 2017. A competitive inhibitory circuit for selection of active and passive fear responses. Nature 542: 96-100.

Fenton GE, Halliday DM, Mason R, Bredy TW, Stevenson CW. 2016. Sex differences in learned fear expression and extinction involve altered $\gamma$ oscillations in medial prefrontal cortex. Neurobiol Learn Mem 135: $66-72$.

Glover EM, Jovanovic T, Mercer KB, Kerley K, Bradley B, Ressler KJ, Norrholm SD. 2012. Estrogen levels are associated with extinction deficits in women with posttraumatic stress disorder. Biol Psychiatry 72: 19-24.

Gozzi A, Jain A, Giovannelli A, Bertollini C, Crestan V, Schwarz AJ, Tsetsenis T, Ragozzino D, Gross CT, Bifone A. 2010. A neural switch for active and passive fear. Neuron 67: 656-666.

Graham BM, Daher M. 2016. Estradiol and progesterone have opposing roles in the regulation of fear extinction in female rats. Neuropsychopharmacology 41: 774-780.

Gruene TM, Roberts E, Thomas V, Ronzio A, Shansky RM. 2015a. Sex-specific neuroanatomical correlates of fear expression in prefrontal-amygdala circuits. Biol Psychiatry 78: 186-193.

Gruene TM, Flick K, Stefano A, Shea SD, Shansky RM. 2015b. Sexually divergent expression of active and passive conditioned fear responses in rats. Elife 4: e11352.

Kessler RC, Sonnega A, Bromet E, Hughes M, Nelson CB. 1995. Posttraumatic stress disorder in the national comorbidity survey. Arch Gen Psychiatry 52: 1048-1060.

Kilpatrick DG, Resnick HS, Milanak ME, Miller MW, Keyes KM, Friedman MJ. 2013. National estimates of exposure to traumatic events and PTSD prevalence using DSM-IV and DSM-5 criteria. J Trauma Stress 26: $537-547$.

Lebron-Milad K, Milad MR. 2012. Sex differences, gonadal hormones and the fear extinction network: implications for anxiety disorders. Biol Mood Anxiety Disord 2: 3.

Maren S, De Oca B, Fanselow MS. 1994. Sex differences in hippocampal long-term potentiation (LTP) and pavlovian fear conditioning in rats: Positive correlation between LTP and contextual learning. Brain Res 661: $25-34$.

Matsuda S, Matsuzawa D, Ishii D, Tomizawa H, Sutoh C, Shimizu E. 2015. Sex differences in fear extinction and involvements of extracellular signal-regulated kinase (ERK). Neurobiol Learn Mem 123: 117-124.

Milad MR, Quirk GJ. 2012. Fear extinction as a model for translational neuroscience: ten years of progress. Annu Rev Psychol 63: 129-151.

Milad MR, Igoe SA, Lebron-Milad K, Novales JE. 2009a. Estrous cycle phase and gonadal hormones influence conditioned fear extinction. Neuroscience 164: 887-895.

Milad MR, Pitman RK, Ellis CB, Gold AL, Shin LM, Lasko NB, Zeidan MA, Handwerger K, Orr S, Rauch SL. 2009b. Neurobiological basis of failure to recall extinction memory in posttraumatic stress disorder. Biol Psychiatry 66: 1075-1082.

Norrholm SD, Jovanovic T, Olin IW, Sands LA, Karapanou I, Bradley B, Ressler KJ. 2011. Fear extinction in traumatized civilians with posttraumatic stress disorder: Relation to symptom severity. Biol Psychiatry 69: 556-563.

Parsons RG, Ressler KJ. 2013. Implications of memory modulation for post-traumatic stress and fear disorders. Nat Neurosci 16: 146-153.

Rey CD, Lipps J, Shansky RM. 2014. Dopamine D1 receptor activation rescues extinction impairments in low-estrogen female rats and induces cortical layer-specific activation changes in prefrontal-amygdala circuits. Neuropsychopharmacology 39: 1282-1289.

Steenbergen HL, Heinsbroek RP, Van Hest A, Van de Poll NE. 1990. Sex-dependent effects of inescapable shock administration on shuttlebox-escape performance and elevated plus-maze behavior. Physiol Behav 48: 571-576.

Toufexis D, Davis C, Hammond A, Davis M. 2005. Sex differences in hormonal modulation of anxiety measured with light-enhanced startle: Possible role for arginine vasopressin in the male. J Neurosci 25: 9010-9016.

Walker DL, Davis M. 2002. Quantifying fear potentiated startle using absolute versus proportional increase scoring methods: Implications for the neurocircuitry of fear and anxiety. Psychopharmacology 164: $318-328$.

Wood GE, Shors TJ. 1998. Stress facilitates classical conditioning in males, but impairs classical conditioning in females through activational effects of ovarian hormones. Proc Natl Acad Sci 95: 4066-4071.

Yu K, Garcia da Silva P, Albeanu DF, Li B. 2016. Central amygdala somatostatin neurons gate passive and active defensive behaviors. $J$ Neurosci 36: 6488-6496.

Received March 16, 2017; accepted in revised form April 4, 2017. 


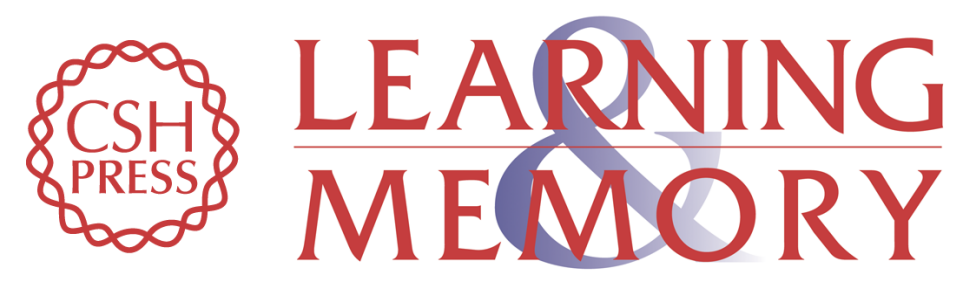

\section{Response-specific sex difference in the retention of fear extinction}

Meagan E. Voulo and Ryan G. Parsons

Learn. Mem. 2017, 24:

Access the most recent version at doi:10.1101//m.045641.117

References This article cites 33 articles, 5 of which can be accessed free at: http://learnmem.cshlp.org/content/24/6/245.full.html\#ref-list-1

Creative This article is distributed exclusively by Cold Spring Harbor Laboratory Press for the Commons first 12 months after the full-issue publication date (see

License http://learnmem.cshlp.org/site/misc/terms.xhtml). After 12 months, it is available under a Creative Commons License (Attribution-NonCommercial 4.0 International), as described at http://creativecommons.org/licenses/by-nc/4.0/.

Email Alerting Receive free email alerts when new articles cite this article - sign up in the box at the Service top right corner of the article or click here. 